\title{
LA CRÍTICA LITERARIA CONSERVADORA EN COLOMBIA ENTRE 1930 Y $1950^{*}$
}

\author{
The Conservative Literary Criticism in \\ Colombia Between i930 and i950
}

Leonardo Augusto Monroy Zuluaga ${ }^{1}$

\begin{abstract}
* Artículo derivado de la investigación "El pensamiento literario de Rafael Gutiérrez Girardot entre 1970 y 1990 y sus relaciones con América Latina", del Grupo de investigación en Literatura del Tolima.
\end{abstract}

Cómo citar este artículo: Monroy Zuluaga, L. A. (2021). La crítica literaria conservadora en Colombia entre 1930 y 1950. Estudios de Literatura Colombiana 49, pp. 105-119. DOI: https://doi.org/10.17533/udea.elc.n49a06

1 https://orcid.org/ 0000-0001-6760-8932 Imonroyz@ut.edu.co Universidad del Tolima, Colombia

Editores: Andrés Vergara Aguirre, Christian Benavides Martínez

Recibido: 15.02 .2021

Aprobado: 21.05.2021

Publicado: 30.06 .2021

Copyright: (2021 Estudios de Literatura Colombiana. Este es un artículo de acceso abierto distribuido bajo los términos de la Licencia Creative Commons AtribuciónNo comercial - Compartir igual 4.0 Internacional
Resumen: Este artículo interpreta algunas características de la crítica literaria conservadora en Colombia entre 1930 y 1950, enfatizando en las propuestas de Laureano Gómez, Antonio Gómez Restrepo y Rafael Maya. Para el análisis se retoma la categoría de "repertorio" de Itamar Even-Zohar, desde la cual se comprende el peso del ejercicio crítico en el circuito literario, al tiempo que se ofrece un espacio para establecer diálogos entre varios estudiosos. El documento pone de relieve la fuerte sujeción de los repertorios críticos conservadores a los principios religiosos y la importancia de la poesía clásica como forma mayor dentro de la jerarquía de los géneros.

Palabras Clave: crítica literaria conservadora; Laureano Gómez; Antonio Gómez Restrepo; Rafael Maya.

Abstract: This paper interprets some characteristics of the Colombian conservative literary critics between 1930 and 1950, focusing on the ideas of Laureano Gómez, Antonio Gómez Restrepo and Rafael Maya. For the analysis, the category of "repertoire" by Itamar Even-Zohar helps to understand the relevance of literary criticism in the literary circuit and, at the same time, it gives rise to suggest a dialogue between several thinkers. This paper highlights the significance of religious beliefs in the repertoire of conservative literary critics, and the strong presence of classical poetry as a major literary genre.

Key words: Conservative literary criticism; Laureano Gómez; Antonio Gómez Restrepo; Rafael Maya. 


\section{Introducción}

El periodo entre 1930 y 1950 fue política y socialmente turbulento en Colombia. El punto de inicio significó la vuelta de un gobierno del partido liberal luego de más de tres décadas de hegemonía conservadora y, por momentos, la búsqueda de un Estado democrático en el que hubiera una distribución equitativa de la tierra y educación laica para todos. Así mismo, y como señalaban con indignación los alfiles del partido conservador años después, reformas constitucionales como la de 1936, hechas por un gobierno liberal, afectaban pilares del pensamiento conservador, como "la libertad de conciencia, la libertad de cultos, la prohibición del clero de intervenir en política" (Ayala Diago, 1995, p. 21). Pese a algunos avances, y debido a conflictos no solucionados entre los integrantes de los dos partidos tradicionales en Colombia, en 1948 estalló lo que se conoce como la Violencia, un feroz enfrentamiento especialmente entre las clases menos favorecidas. El conflicto se intensifica luego de 1950, cuando se produce el ascenso de Laureano Gómez a la presidencia, y con él la implementación de políticas regresivas y el recrudecimiento de las persecuciones a los integrantes del partido liberal.

Como es el signo común de toda crítica literaria, pero tal vez con mayor acentuación por el momento histórico que sufría el país, entre 1930 y 1950 la crítica conservadora se tornó en una opción ético-política que buscaba detener las corrientes modernas - $\mathrm{y}$ en general, las alejadas del universo católico-, derrotar a sus adversarios liberales y fortalecer la formación de una cultura nacional arraigada en su fidelidad a España, su lengua y su religión. Con esto en mente, cuando se habla de crítica conservadora no solo se está haciendo énfasis a la adhesión a un partido político, sino en general a una cosmovisión que afecta todas las esferas de la cultura. En este sentido, el pensamiento conservador se define por el lugar y el momento de la enunciación, y aunque hay rasgos que se reiteran en diferentes escenarios, "no significa siempre lo mismo [...], es una noción diferencial, comparativa, no ontológica" (García, 2017, p. 143).

En las líneas siguientes se analizará detalladamente esa tendencia, teniendo en cuenta tres voces representativas: Laureano Gómez, Antonio Gómez Restrepo y Rafael Maya. Las fuentes utilizadas en esta exploración son los libros de crítica literaria publicados por estos tres ensayistas entre 1930 y 1950, así como artículos y ensayos de dos publicaciones periódicas de vital importancia hacia la época estudiada: la separata Páginas Literarias del diario El Siglo, y la Revista del Colegio Mayor de Nuestra Señora del Rosario. 
Para abordar esa crítica literaria conservadora en las décadas señaladas se retoma la propuesta del crítico israelí Itamar Even-Zohar quien, tras interrogar las corrientes de interpretación concentradas exclusivamente en la evaluación textual, propone que existen factores externos a la obra que inciden en el circuito literario. Uno de esos factores es, precisamente, la crítica literaria. Sobre el particular, Even-Zohar (2017) invita implícitamente a explorar las líneas básicas del pensamiento de los estudiosos de la literatura desde el concepto de repertorio, esto es, "el agregado de reglas y materiales que rigen tanto la confección como el uso de cualquier producto" (p. 42). Cada intelectual tiene sus propias reglas y las expone en los círculos académicos con el fin de legitimar cierta manera de ver el fenómeno literario en una sociedad determinada.

El presente artículo encarará algunas de esas reglas de los críticos conservadores planteando ideas afines que permitan comprender el conjunto, desde el diálogo de cada una de las partes. En este sentido, de la lectura de los documentos fuente se ha distinguido dos líneas generales que conforman el repertorio de los críticos conservadores y que se explorarán a continuación: el peso religioso que recaía sobre su mirada y la jerarquía de los géneros literarios que se construyó desde sus principios.

\section{El peso religioso}

Pese a las contradicciones del pensamiento conservador en Colombia, previo a la década de 1930 (que tuvo algunos matices incluso en defensa de valores democráticos y laicos), tal cosmovisión estuvo fuertemente influida por la Iglesia católica, al punto de convertirse en un "rasgo decisivo" (Arias Trujillo, 2018, p. 228), en una suerte de trasfondo ideológico ineludible. En términos generales, hacia la época "la visión católica estará definida por su extremado antiliberalismo, anticomunismo y antiprotestantismo" (Turriago, 2017, p. 70), tres posiciones cosechadas tanto a nivel local como internacional. Así las cosas, varios de quienes ejercieron la labor de críticos literarios desde este universo conservador fueron afectados por las ideas religiosas que en ocasiones dirimieron conflictos estéticos.

Si bien aún no es reconocido como una voz determinante en el campo de los estudios literarios colombianos, el ensayista que con mayor evidencia puede ser ubicado en el círculo de la crítica conservadora entre 1930 y 1950 es Laureano Gómez. Su presencia política concitaba polémicas, fuera que su expresión se sintiera en forma de proclamas inflamadas, textos de apreciación estética o incluso obras literarias. 
Sus ensayos son una muestra de conocimiento de la sintaxis y el léxico castellano a la vez que, en la mayoría de los casos, emanan una fuerte ironía con la que se enfrentaba a sus adversarios.

Gómez fue quien con mayor vehemencia quiso trasplantar su visión del mundo a todos los ámbitos en los que se desempeñó, incluyendo el de la crítica literaria. Era un católico convencido de que la religión salvaría la humanidad y a esa fe le sumaba la idea de que las naciones que se habían apartado de la Santa Madre Iglesia eran castigadas con el caos y la degeneración. Veía en las corrientes liberales la intromisión demoniaca y se imaginaba que el mundo occidental estaba asechado por una conspiración de masones, judíos y comunistas (Henderson, 1985, p. 146). Durante las décadas de 1930 y 1940 radicalizó su posición frente al partido liberal —que estuvo gran parte de esta época en el poder- y persiguió con celo inquisitorio cualquier formulación hecha por sus adversarios políticos.

En el ámbito literario arremetió contra los colaboradores de los primeros números de la Revista de Indias (1936-1951), patrocinada en ese entonces por el gobierno liberal de Alfonso López Pumarejo. Así, por ejemplo, se puede recordar la disputa que desata en Laureano Gómez la publicación del número 5 de dicha revista (marzo de 1937), dedicado en su totalidad al poeta Federico García Lorca, asesinado por el franquismo en la guerra civil. Con el dolor de la pérdida reciente, en el número aparecen textos críticos sobre la vida y obra del poeta español, realizados por, entre otros, Rafael Maya, Lino Gil Jaramillo, Raúl Roa, Melchor Fernández Almagro, así como poemas en homenaje a la memoria de García Lorca con autoría de Darío Samper y Eduardo Carranza.

Una conmemoración de un poeta afín a la izquierda era indignante para Laureano Gómez, pero lo que suscita la mayor cantidad de invectivas de su parte es el epistolario entre Federico García Lorca y Jorge Zalamea. Se debe recordar acá que, desde la década de 1920 en Colombia, la izquierda era vista por los sectores más reaccionarios del país como "la culpable de la agitación social y la lucha de clases" (Arias Trujillo, 2018, p. 223) y, pese a que internamente la izquierda tenía poco poder hacia la época, Laureano Gómez insistía en relacionarla con los liberales, que en conjunto debían ser combatidos con el traje de la Iglesia católica. Así, luego de un repaso fonético y gramatical de los poemas de Porfirio Barba Jacob - un enfoque crítico en el que Gómez se deleitaba-, cierra el ensayo titulado "Clave de ciertas admiraciones" 
(1937), aparecido en el periódico El siglo de Bogotá bajo el seudónimo de Jacinto Buenaventura, con las siguientes palabras:

Entre nosotros, en la execrable Revista de indias, se ha tenido la avilantez de publicar los facsímiles de unas cartas mariconas y una especie de romance del marica del citado García Lorca. Y iesta es una publicación oficial, hecha por el ministerio de educación, bajo el afrentoso gobierno de Alfonso López! (Gómez, 1984, p. 72).

Al margen de la posible sorpresa por el lenguaje ofensivo, esta afirmación puede ser leída a la luz de sus connotaciones. Apunta aquí Laureano Gómez hacia varios flancos: en el ámbito local trata de deslegitimar el gobierno del presidente López Pumarejo, quien, además de su entusiasmo por la Revista de Indias, había promovido la mayor cantidad de leyes para modernizar al país, entre ellas una reforma agraria y el deslinde de la educación frente a la Iglesia católica. Insultaba asimismo a Jorge Zalamea (acusado de ser el marica que lleva un romance con García Lorca), uno de los principales bastiones en el ámbito cultural y educativo del gobierno de Alfonso López Pumarejo. Arremetía contra Federico García Lorca, quien se había opuesto a la dictadura de Francisco Franco en España, dictadura con la que Gómez guardaba una sutil connivencia (Henderson, 1985, p. 140). Profesaba, por último y con orgullo, su condición de católico militante al repudiar las relaciones homosexuales.

Este episodio es una muestra de la constante injerencia de la posición axiológica de Gómez en sus ejercicios de lectura. Precisamente en casi todos sus ensayos de crítica se despliega ese arsenal de guerrero de la santidad con el que se revelan más sus convicciones religiosas que estéticas. Los textos publicados entre 1936 y 1942 expresan esa línea: por ejemplo, sobre Itinerario de fuga de José Umaña Bernal concluye que lo peor es su "rastrera sensualidad” (Gómez, 1984, p. 33); el libro de poesía de Darío Samper es un "folleto detestable, mal oliente, asqueroso" (p. 67) porque "todo lo observa desde el aspecto inmundo" (p. 66); la poesía de Barba Jacob es "refugio para extraviados y cobardes" (p. 105); sobre Stefan Sweig afirma que es un ser maligno, con intenciones anticristianas (p. 117). De este matiz eran las lecturas de Laureano Gómez, que en todos los ámbitos públicos se mantuvo fiel a una cerrada noción conservadora de la sociedad y entendió la literatura casi como una expresión ancilar de los proyectos religiosos.

Un tanto menos radical, aunque afín en varios sentidos, es la postura de Antonio Gómez Restrepo. Pese a que Gómez Restrepo venía ejerciendo su labor interpretativa desde comienzos del siglo xx, es entre 1930 y 1950 que empieza a tener fuerte 
figuración, en una dupla que, junto con Rafael Maya, conformaba la cima de la visión conservadora en el ensayo de crítica literaria hacia la época. ${ }^{1}$

Gómez Restrepo se declara fiel seguidor de los preceptos de Miguel Antonio Caro y, como él, pretende integrar las teorías de Sainte Beuve e Hipólito Taine, pero una mirada detenida a sus escritos revela un compromiso adicional. Es probable que él mismo quisiera borrar las huellas de sus intenciones un tanto monacales porque en las primeras líneas de su Historia de la literatura colombiana está interesado en demostrar que guarda una perfecta neutralidad. Dice en ellas:

El autor sólo aspira a que se reconozca su buena voluntad, su deseo de no omitir nada que interese al cabal conocimiento de nuestro desarrollo literario; y la imparcialidad de su criterio, que jamás se ha guiado por razones extrañas al arte, ni ha tenido en cuenta motivos de orden político o personal (Gómez Restrepo, 1946, p.9).

Esta imparcialidad será la que pondrá en relieve unos años más tarde Rafael Maya, sucesor de Gómez en la cátedra de literatura en el Colegio Mayor de Nuestra Señora del Rosario. En su artículo "Antonio Gómez Restrepo, poeta y crítico", Rafael Maya (s. f.) recordará cómo, a pesar de las diferencias, Gómez Restrepo valoró positivamente, y en un momento políticamente vibrante, la obra de José Asunción Silva y Carlos Arturo Torres (p. 298). Una impresión similar —y más recientetiene Hernando Urriago Benítez (2007), quien afirma que la Historia de la literatura colombiana de Gómez Restrepo "está compuesta por notas agudas y ecuánimes que de alguna manera seguían la tradición filológica legada por la generación del siglo anterior" (p. 50).

Sin embargo, es difícil deslindar la lectura de los textos de Gómez Restrepo de su militancia religiosa, y el carácter conservador de su estilo y de su visión. Aunque en su crítica trata de involucrar diferentes perspectivas al uso en su época - y de esta forma darle un matiz científico a su interpretación-, son cuanto menos sintomáticas las aseveraciones que aparecen repetidamente en sus ensayos y que buscan reafirmar su complacencia frente al hecho de que nuestros escritores fueran católicos.

Basta recordar algunas de las apreciaciones con las que apuntalaba sus textos críticos: de José Eusebio Caro afirmaba que “vendrán los jóvenes a recibir de ese

Así se le reconoce en la introducción de su libro Crítica literaria (1935) y en los artículos de "Antonio Gómez Restrepo. Poeta y Crítico" (1946) de Raimundo Rivas, y “Antonio Gómez Restrepo. Crítico literario" (1947) de Cecilia Hernández de Mendoza, además de que gran parte de la producción crítica de Antonio Gómez Restrepo fue publicada en el periodo estudiado. 
mármol, elocuente en su olímpica mudez, altas lecciones de amor patrio, de virtud estoica, de dignidad cristiana; y él les enseñará que la filosofía utilitarista corrompe las naciones” (Gómez Restrepo, 1935, p. 133); José Joaquín Ortíz es un "patriarca cristiano" (p. 137); José Caicedo Rojas dedicó su vida al cultivo de la "religión y de la patria" (p. 147); Diego Fallon, egregio poeta, "esperó la muerte aferrado al crucifijo" (p. 162).

Para Gómez Restrepo la figura del escritor se engrandecía con su filiación religiosa. En ese sentido se sentía cómodo al encontrar un canon de obras y autores colombianos en los que no hubiera duda de la sustancia católica y constantemente fortalecía la afirmación que realizó en la introducción de su Historia de la literatura colombiana: la literatura y la cultura del país "aparecen hondamente marcadas con un sello cristiano y castizo" (Gómez Restrepo, 1946, p. 10). A la distancia de varias décadas, y fiel a su postura conservadora, Gómez Restrepo continuaba la discusión que los diseñadores de parnasos y antologías habían desarrollado hacia el siglo XIX en el país, y con disimulada ortodoxia respondía a la pregunta sobre "qué enseñar, y cuáles valores son los más representativos para transmitirse” (Guzmán, 2009, p. 102).

Por esta razón, incluso frente a obras profanas como "La hora de las tinieblas" de Rafael Pombo, perseveró en su defensa de la religión sin demeritar el trabajo del poeta colombiano. En esta senda, el artículo dedicado a Pombo (Gómez Restrepo, 1935) combina rasgos biográficos con un repaso a las principales obras del autor, realizando comparaciones con otros escritores y escudriñando filones temáticos y estilísticos. Pombo goza de la admiración de Gómez Restrepo, aunque se presenta un inconveniente ético cuando el crítico encara el poema "La hora de las tinieblas", este último plagado de escepticismo y en ocasiones injurioso.

Gómez Restrepo (1935) trata de quitar peso a esta creación que no concuerda con la imagen religiosa a la que es proclive: inicialmente advierte que su primera versión fue dada a conocer sin la anuencia de Pombo; luego dice que el poema había sido escrito en un "momento de exasperación por una dolencia física” (p. 88), para después recordar que en este tipo de obras "la apreciación ética y literaria tienen que diferir profundamente" (p. 91).

Hacia el final del ensayo insiste en que la obra completa de Pombo está "animada por el más puro sentimiento religioso" (p. 99) e incluso, como una forma de expiación ajena, divisa el poema "De noche" — este sí en el camino del buen sama- 
ritano- como el testamento poético del autor de "Rin rin renacuajo", a la vez que como la "verdadera respuesta a La hora de las tinieblas" (p. 111). Esa imagen final, que absorbe cualquier caída previa de Rafael Pombo, es la que desea destacar Antonio Gómez Restrepo. Así reintegra al poeta a una tradición literaria nacional que respeta los preceptos católicos y en la que se ubican los creadores más importantes.

El componente que domina la crítica de Gómez Restrepo es, en la misma vía de Laureano Gómez, aunque menos radical, el de la religión católica. Como lo afirmó el primero, "la poesía es eco humano de la revelación divina" (p. 124), los escritores tienen más virtudes en la medida en que den muestras de su fe y, en general, la cultura y la literatura del país son talladas por el cristianismo.

Un tercer caso es el de Rafael Maya, quien sostuvo relación con intelectuales de uno y otro partido político. Basado en esta doble experiencia, por un lado, se alineó al espíritu de la cultura clásica que "comprendía dos vertientes fundamentales: el mundo clásico antiguo y la tradición española” (Jiménez Panesso, 1992, p. 38) e insistió en una crítica con énfasis en principios trascendentes y con cierta empatía con el catolicismo, aunque como se explorará en las próximas líneas, en algunos momentos distanciada de la fe cristiana. Por otro lado, participó en la revista Cromos y en la generación constituida por un grupo de intelectuales reunidos alrededor de la publicación titulada Los Nuevos, aparecida en 1925, un poco más abierta a ideas renovadoras.

Es en el tomo 1 de Alabanzas del hombre y de la tierra (1934) donde más se aferra a la crítica de corte clásico, cuyos principios explicitará hacia 1944 en el conocido estudio Consideraciones críticas sobre la literatura colombiana. Allí se observa la obra desde "el gusto por el orden, la claridad, la medida y la adecuada relación entre el fondo y la forma" (Maya, 1944, p. 18), aunque a estos conceptos, y de acuerdo con Maya, "es preciso arrancarles la careta retórica y considerarlos en la idea misma, como virtudes del entendimiento y no como efectos del tecnicismo gramatical” (p. 19).

Esta concepción clásica de la literatura, devenida de las entrañas mismas del campo artístico, gravitó, por momentos, más que sus convicciones religiosas. No de otra forma se podría explicar la lectura que realiza sobre José Asunción Silva en el nombrado libro de las Alabanzas. E1 texto sobre Silva, que originalmente fue una conferencia dictada en el teatro Municipal de Bogotá, traza varios de los caminos que con posterioridad ampliarán otros lectores de la obra del poeta bogotano: su capacidad para sugerir sensaciones y significados desde la palabra, en un ejercicio que 
lo acerca al simbolismo; el carácter de dandy; la oposición que logró Silva con éxito frente al romanticismo.

La lectura de Maya es aguda en varios de estos renglones, pero lo que más llama la atención es el freno que interpuso a algunas de sus convicciones axiológicas a favor de una interpretación netamente estética. Su fe cristiana no le impide acercarse a José Asunción Silva, de quien afirma que profesó una angustia de origen laico (Maya, 1934, p. 15), su genio fue propiciado por los tres enemigos del alma (la experiencia, el mundo, la carne) (p. 25), bebió de las fuentes de Nietzsche y Barres (p.26) y, aunque previó las consecuencias de las teorías sensualistas (p. 27), no cesó en su voluntad de vivir plenamente (p. 30).

Como conservador, Maya va más allá de los límites permitidos por la Iglesia católica en sus versiones más ortodoxas. Desde allí era impensable que un intelectual se arriesgara a elevar a la categoría de genio a un escritor en cuyo seno trasegaban los bastiones de la modernidad: la secularización, la desmiraculización de la cultura, el materialismo, son algunas de las facetas contra las que obcecadamente habían luchado las facciones tradicionales en Colombia y que Maya mira con objetividad.

Maya divisó a Silva — pero también a Porfirio Barba Jacob e incluso a Baldomero Sanín Cano- desde criterios netamente estéticos. Para el autor de las Alabanzas $-\mathrm{y}$ tal vez con mayor fuerza en ese libro— fue más importante la correspondencia entre fondo y forma que el estímulo religioso de los autores y las obras. Por esta razón su interpretación de Silva tiene como colofón el hecho de que

Su obra es eterna, con la diferencia de que lo es, contra el sentido común, no porque hubiera expresado nuestros dolores o servido de eco a nuestros desengaños y esperanzas [...] sino porque, inversamente, a través de una forma pura, equilibrada, sabiamente ceñida, universalizó modos de sentir que eran suyos propios (Maya, 1934, p. 45).

Sin embargo, Maya va cambiando paulatinamente y de estas expresiones de 1934 a su libro aparecido una década más tarde (Consideraciones críticas sobre la literatura colombiana), el matiz religioso se irá endureciendo. De por medio está la explosión de la Segunda Guerra Mundial que dejó a muchos intelectuales con el convencimiento de que la modernidad había fracasado y se debería borrar sus impulsos, tatuados, en este caso, en la literatura. Así mismo, vivió durante estos años, en el plano local, los alcances de las políticas liberales, en especial en lo que tenía que ver con una concepción laica de la educación y de la cultura en general, lo que tal vez lo llevara a una militancia más protagónica. 
Acaso algunas de estas circunstancias hayan labrado un Maya un poco menos transigente con las ideas modernas por lo que en las Consideraciones críticas lo vemos despacharse en contra del "dogma de la tolerancia” (Maya, 1944, p. 83), cuyas consecuencias son, entre otras, el haber "venido a sustituir a la antigua noción clásica y cristiana de la vida” (p. 83) y haber propiciado la exploración del materialismo, los temas sexuales y la flexibilidad en términos de composición de los géneros literarios. Sin embargo, mantiene aun tímidamente su visión positiva sobre José Asunción Silva, Porfirio Barba Jacob — de quien afirma en este libro que es un "ejemplo de sinceridad poética en el dolor” (p. 39) - y Baldomero Sanín Cano, quien como crítico literario era casi su antítesis.

Rafael Maya luchó - en especial en sus primeras etapas- por concentrarse en una lectura de la obra literaria que cumpliera con las reglas del arte clásico y se alejara de prejuicios católicos o partidistas, para lo cual fueron clave no solo sus lecturas sino las redes intelectuales en las que participó. Ese gesto se fue apagando, en especial si se tiene en cuenta que con el trascurrir de los años consideraría que "el rasgo fundamental del país es su espíritu religioso" (Maya, 1945, p. 3). Como crítico se negó a ser moderno y esa negativa ha quitado actualidad a su propuesta, sacudida por contradicciones axiológicas resueltas con su permanencia en la fe, tal como lo profesaron sus dos grandes compañeros de época: Laureano Gómez y Antonio Gómez Restrepo.

\section{La poesía clásica como expresión mayor}

Por razones estéticas, políticas y éticas, la poesía - y específicamente la poesía clásica- fue el género privilegiado por los ensayistas de crítica literaria conservadora. Ella se concebía en Colombia desde sus rasgos tradicionales, que se pueden resumir en los siguientes ejes: una tendencia al orden y la claridad; el afán de impersonalidad y de universalidad, con la que se pretendía encontrar ideas inmutables y relievar la grandeza; la perfección formal y el apego a las reglas de composición poética; la íntima relación entre arte y moral que creaba a su vez una mezcla indisoluble entre lo bello y lo verdadero; el equilibrio entre el pensamiento o la emoción y la forma, y la tendencia a la imitación de los clásicos griegos y latinos.

Con estos antecedentes, hubo una constante necesidad de respetar y hacer respetar la norma lingǘstica al uso, en una línea que, como lo pone de relieve Diana Guzmán (2009), retomando a Beatriz González, era bastión del pensamiento con- 
servador desde el siglo XIX, y tenía entre sus características "la estructuración de una literatura nacional fundamentada en el principio de la unidad lingüística” (p. 95). En atención a este hecho, la preocupación por el preciosismo verbal — que en ocasiones deriva en floritura y retórica- se presenta en estos ensayistas conservadores. Fieles a su credo en una forma considerada por ellos la más elevada, no solo escribieron de una manera refinada y lingüísticamente perfecta, sino que se enfrentaron con denuedo a las corrientes poéticas que experimentaban con el lenguaje, afincadas en algunos de los escritores hispanoamericanos y colombianos.

En esta vía, desde la década de 1930 Laureano Gómez defendía la poesía clásica apoyado en sus conocimientos de la estilística. Tenía claro que las vanguardias poéticas penetraban paulatinamente en el país y que en la mayoría de los casos eran sus opositores políticos quienes llevaban a cabo la herejía de asumirlas. En 1936 escribía en el periódico El siglo: "ahora los versos que más aplausos coleccionan son los que han roto con mayor audacia las antiguas sujeciones de la métrica clásica y se reducen a una forma libre, vaga, generalmente asonantada, sarpullida de vocablos exóticos" (Gómez, 1984, p. 22).

Con esos temores leyó de manera radical a quienes se desviaban de sus principios estéticos y políticos. Se debe recordar, por ejemplo, las evaluaciones realizadas hacia los años que interesan a este estudio, a León de Greiff —uno de los poetas que más experimentó con la musicalidad del verso en Colombia-, José Umaña Bernal, Federico García Lorca, Darío Samper y Pablo Neruda. En todas ellas hay una mezcla casi intimidante de conceptos gramaticales y sintácticos (su crítica está llena de anapestos y anfíbocos, de alejandrinos, octavas, etc.) unidos a su sectarismo ideológico que conducía a conclusiones similares: los poetas alejados de su mirada católica - y, por lo tanto, peligrosamente modernos- no conservaban el ritmo, su léxico era pobre, y sus metáforas poco claras. Eran, en el mejor de los casos, "poetas del régimen" liberal o engendros de payasos.

Una percepción similar, aunque menos álgida, se observa en Rafael Maya. En sus Consideraciones criticas, Maya hace un duro balance de la literatura nacional, no se aleja de sus principios y mantiene la poesía clásica en el primer rango de la escala jerárquica. Para él hay una línea divisora entre las escuelas o corrientes que han sabido perfeccionar la forma - en las cuales el sentimiento o el pensamiento tienen una indisoluble relación con la expresión - y aquellas que han degenerado en simple 
verbalismo que oculta la vaciedad ideológica. En el primer caso está la poesía clásica, mientras que en el segundo, con algunas excepciones (Pombo, Fallon, Darío, Apollinaire, entre otros), se encuentran las corrientes del romanticismo, el modernismo, y las vanguardias poéticas (Maya, 1944, p. 120).

Esta crítica se convertía en una suerte de defensa de los principios de la humanidad, que comprendían la fe católica, las buenas costumbres, la paz, el progreso social y la armonía entre los hombres. Se tenía la convicción, como se entiende en las ideas de Rafael Maya en 1944, de que una poesía que no fuera fiel a los principios católicos y clásicos promovía la degeneración de la civilización y por lo tanto debía ser rechazada. Por esta razón, Maya pone en entredicho las teorías de José Ortega y Gasset sobre la deshumanización del arte, porque ve en ellas la justificación de una literatura caótica, correlato de la sociedad contemporánea. Así mismo, la emprende contra el freudismo, que con su carga de irracionalidad promovía las "desviaciones"; otro tanto ocurría con las vanguardias poéticas que fueron sinónimo del desorden social, solo subsanable con la vuelta a la mano de Dios (Maya, 1944, p. 121).

Para estos críticos, el caos estaba presente en todos los ámbitos y había que atacarlo con entereza: Freud, el futurismo, el expresionismo, el modernismo, la Primera y la Segunda Guerra Mundial, la entrega de la educación a instituciones laicas, la salida de la administración pública de los presidentes gramáticos y poetas, el liberalismo, el marxismo, el positivismo y, hacia finales de este periodo, el existencialismo, con su carga de ateísmo que enardecía a quienes profesaban la fe en Dios. ${ }^{2}$ El país se salvaría con el predominio de la poesía clásica y una devoción religiosa que se hallaba casi intacta en España.

Gran parte de la suerte de la novela en Colombia a principios del siglo xx se fundó en esta visión negativa sobre los productos de la modernidad que se alejaban de la visión clásica. ${ }^{3}$ Como lo anotan Arango y Fernández (2011), para David Jiménez Panesso existía un antecedente en Miguel Antonio Caro quien tenía el prurito frente a la novela "por el peligro que acarrea mostrar la realidad de manera directa, sin ideas

2 Contra Jean-Paul Sartre se cargaban muchas tintas: ver por ejemplo "El existencialismo" (1950) de Ignacio Escobar López y “Las conferencias existencialistas”(1950) de Ảlvaro Sánchez en la separata Páginas Literarias del diario El Siglo.

3 La contraparte de la posición conservadora prefirió no encarar la literatura nacional y solo en el final del periodo estudiado, Jorge Zalamea (1978) realiza un fino análisis de la literatura colombiana, titulado “Tomás Carrasquilla y la literatura colombiana", incluido en Literatura, política y arte, en el que involucra géneros desdeñados por los críticos conservadores, como la novela y el teatro. 
ni enseñanzas morales" (p. 45). Como lo muestran las disputas de principio de siglo xx en Colombia (Jimenez Panesso, 1992; Arango y Fernández, 2011), inicialmente se satanizó la novela naturalista, con Émile Zola a la cabeza. A dicho tipo de expresión se le imputaba una tendencia sórdida mediante la cual solo se mostraban las facetas oscuras del ser humano.

Posteriormente, con la popularización de la novela que experimentaba en la forma y en el contenido — como Ulises de James Joyce-, el rechazo frente a los valores en ella promulgados se iba acentuando. Aunque no existía mucha conciencia del origen y desarrollo del género de la novela, era evidente que para los críticos conservadores fue difícil aceptar el paso avasallador de la modernidad, y con ella la "prosa del mundo"; esto es, según Rafael Gutiérrez Girardot (2004), un "estado en el que el arte ha dejado de ser la más alta forma en la que se manifiesta la verdad y el más alto menester del espíritu” (p. 44). En este mundo de preocupaciones prosaicas, la novela se había erguido como la forma más adecuada para observar al ser humano en sus disyunciones, arrinconado por una sociedad en la que los individuos eran egoístas y el escepticismo frente a una verdad omnipotente y extraterrena ganaba espacio en las conciencias.

La exploración de la ambigüedad del ser humano y la presentación de personajes que se alejaban constantemente de la fe en Dios, unidos a un frecuente cambio en las formas de narrar que trastocaban las convenciones y el orden tradicional, hicieron del género novelístico una fuente sospechosa para quienes ejercían una mirada conservadora al arte. Por eso el ensayo de crítica literaria en Colombia, desde esta estructura de evaluación y expresión, le cerró las puertas a la novela, a la que velada o abiertamente omitía.

Las consecuencias de este rechazo fueron, en primera instancia, el tímido acercamiento a los novelistas: no disfrutaron de amplias digresiones, ni el anticlerical José María Vargas Vila ni las obras de Clímaco Soto Borda, entre ellas Diana la cazadora (1917). Tampoco concitaron la mirada autores con una producción más cercana a la década de 1930 como César Uribe Piedrahita y su obra Mancha de Aceite (1935), o José Antonio Osorio Lizarazo y su novela Casa de vecindad (1930), o Cuatro años a bordo de mi mismo (1934) de Eduardo Zalamea Borda. Se encaró medianamente a José Eustasio Rivera y en especial se debe valorar el acercamiento, previo al periodo que se analiza, de Antonio Gómez Restrepo titulado “La vorágine” (Ordoñez Vila, 1987, p. 45). 
El caso de Tomás Carrasquilla fue extraño y excepcional en la crítica conservadora. Su nombre se posicionó paulatinamente en el campo literario colombiano y era innegable que hacia la tercera década del siglo xx en Colombia era reconocido como un prosista destacado. Pero había razones para interrogarlo. Entre ellas se encuentran: el hecho de que Carrasquilla se hubiera salido de la norma castiza para hacer hablar a sus personajes con los giros lingüísticos antioqueños; la exploración de un realismo que mostraba facetas negativas del ser humano; su llamado constante a considerar las entrañas populares como la fuente del alma nacional, en contraposición con lo que pensaban los conservadores, que insistían en que la esencia del colombiano era católica y clásica. Sin embargo, las apreciaciones sobre su obra en Antonio Gómez Restrepo y Rafael Maya son favorables (Montoya, 2008, p. 114). Al margen de esas excepciones (Rivera y Carrasquilla), la posición conservadora vio el género novelístico en general como fuente de los vicios éticos y lingüísticos y no le dio mucha importancia.

Las líneas anteriores confirman que la poesía, especialmente la clásica, fue el fortín conservador. Un país de poetas clásicos que no reñían con el catolicismo no era un anacronismo para los ensayistas de crítica literaria conservadora entre 1930 y 1950, sino un ideal con el que se salvaría la nación. Consecuentemente, la jerarquía de los géneros en la literatura colombiana de la época se definió en gran parte por la influencia de esa posición cuya ruptura solo se logró a partir de fenómenos como la emergencia de una narrativa que quiso dar cuenta de la violencia bipartidista, y por el posicionamiento de Gabriel García Márquez a nivel internacional.

El repertorio común de los estudiosos literarios conservadores se decantó en un tipo de crítica que no logró distanciarse lo suficiente de imperativos religiosos y, en sus versiones más extremas, cumplió una función ancilar, enmascarada con preocupaciones estéticas. Las reglas que intentaron imponer en la producción literaria no obedecían a preocupaciones completamente autónomas y en su momento pudieron haber retrasado el flujo normal de la ciencia literaria en el país y la consolidación de géneros como la novela. Para la historia de la crítica literaria en Colombia estas características del repertorio de los conservadores no han renacido, pero su mirada ha quedado como un momento importante para dilucidar los procesos de los estudios literarios en el país. 


\section{Referencias bibliográficas}

Arango, S. y Fernández, C. (2011). Fundamentos estéticos de la crítica literaria en Colombia. Finales del siglo XIX y comienzos del XX. Medellín: Editorial Universidad de Antioquia.

Arias Trujillo, R. (2018). Conservatismo y catolicismo en Colombia, 1880-1930. En F. Kolar, U. Mucke (Eds.). El pensamiento conservador y derechista en América Latina, España y Portugal. Siglos XIX y XX (pp. 207-230). Frankfurt: Iberoamericana.

Ayala Diago, C. (1995). La reconquista conservadora. Colombia 1957-1958. Historia Crítica 11, pp. 21-38. Even-Zohar, I (2017). Polisistemas de cultura. Tel-Aviv: Universidad de Tel-Aviv/Laboratorio de Investigación de la Cultura. Recuperado de https://bit.ly/3ornZJb [18.05.2021].

García, M. (2017). Notas para una genealogía del pensamiento conservador. Cuadernos de historia 47, pp. 141-163.

Gómez, L. (1984). Obras Completas. Tomo I. Crítica sobre literatura, arte y teatro. Bogotá: Instituto Caro y Cuervo.

Gómez Restrepo, A. (1935). Crítica Literaria. Bogotá: Editorial Minerva.

Gómez Restrepo, A. (1946). Historia de la literatura colombiana. Bogotá: Imprenta Nacional.

Gutiérrez Girardot, R. (2004). Modernismo. Supuestos históricos y culturales. Bogotá: Fondo de Cultura Económica.

Guzmán, D. (2009). Los dueños de la palabra: antologías poéticas en el siglo xix. Estudios de Literatura Colombiana 25, pp. 91-106.

Henderson, J. (1985). Las ideas de Laureano Gómez. Bogotá: Tercer Mundo.

Jiménez Panesso, D. (1992). Historia de la crítica literaria en Colombia. Bogotá: Universidad Nacional de Colombia.

Maya, R. (1934). Alabanzas del hombre y de la tierra. Bogotá: Editorial Santafé.

Maya, R. (1944). Consideraciones críticas sobre la literatura colombiana. Bogotá: Librería Voluntad.

Maya, R. (1945). La educación y el carácter nacional. En Páginas literarias. p. 3.

Maya, R. (s. f.). Antonio Gómez Restrepo. Poeta y Crítico. En Obra Crítica. Sn: se.

Montoya, P. (2008). Tomás Carrasquilla y los críticos colombianos del siglo xx. Estudios de Literatura Colombiana 23, pp. 111-124.

Ordoñez Vila, M. (1987). La vorágine: Textos críticos. Bogotá: Alianza Editorial Colombiana.

Turriago, D. (2017). La actitud de la iglesia católica colombiana durante las hegemonías liberal y conservadora de 1930 a 1953. Cuestiones Teológicas 101, pp. 67-94.

Urriago Benítez, H. (2007). El signo del Centauro: variaciones sobre el discurso ensayístico de Baldomero Sanin Cano. Cali: Programa Editorial Universidad del Valle. 